\title{
Clinical Profile and Outcome of Meconium-Stained Babies Managed in a Tertiary Care Hospital
}

\author{
Rafia Rashid ${ }^{1 *}$, Abid Hossain Mollah², Manisha Banerjee ${ }^{3}$, Syed Shafi Ahmed ${ }^{4}$ and Salahuddin Mahmud ${ }^{5}$ \\ ${ }^{1}$ Department of Pediatric Gastroenterology, Hepatology \& Nutrition, Dhaka Shishu (Children) Hospital, Dhaka, Bangladesh \\ ${ }^{2}$ Professor \& Head, Department of Neonatology, BIRDEM General Hospital, Dhaka, Bangladesh \\ ${ }^{3}$ Professor \& Head, Department of Neonatology, Dhaka Medical College Hospital, Dhaka, Bangladesh \\ ${ }^{4}$ Professor \& Head, Department of Pediatric Gastroenterology, Hepatology \& Nutrition, Bangladesh Institute of Child Health, Dhaka Shishu (Children) Hospital, \\ Dhaka, Bangladesh
}

${ }^{5}$ Associate Professor, Department of Pediatric Gastroenterology, Hepatology \& Nutrition, Bangladesh Institute of Child Health, Dhaka Shishu (Children) Hospital, Dhaka, Bangladesh

*Corresponding author: Rafia Rashid, Department of Pediatric Gastroenterology, Hepatology \& Nutrition, Dhaka Shishu (Children) Hospital, Dhaka, Bangladesh.
Received Date: March 03, 2021

Published Date: April 09, 2021

\begin{abstract}
Objectives: This study evaluates clinicopathological features and the outcome of meconium-stained babies managed in the special care baby unit of Dhaka Medical College Hospital (DMCH), a tertiary care hospital in Bangladesh.

Methods: This observational study was performed in DMCH from $1^{\text {st }}$ March to $31^{\text {st }}$ October 2011. One hundred two neonates with meconiumstained amniotic fluid (MSAF) at birth were selected purposively. Information about the duration of labour, mode of delivery, maternal illness, and maternal medication during pregnancy were recorded. Any other complications like obstructed labour, history of premature rupture of membrane (PROM), history of less fetal movement, history of birth asphyxia were taken from parents and available medical records. Babies' clinical conditions were assessed with APGAR score, birth weight, gestational age, signs of asphyxia, respiratory difficulties, convulsion, reflex activity and requirement of resuscitation, percentage of oxygen saturation, capillary blood glucose (CBG). Other related investigations were also recorded. The outcome of these babies was observed and recorded. Statistical analysis (Chi-square tests) was performed on the recorded data using SPSS (version 24) to identify the association between meconium staining and different clinical features of the newborn.
\end{abstract}

Results: Among the 102 neonates, we found 39 (38.2\%) cases of only meconium staining, 56 (54.9\%) cases of staining with ingestion, and $7(6.9 \%)$ cases of staining with aspiration. Only meconium-stained cases were relatively well alert with normal vital parameters. Other cases of ingestion and aspiration developed complications, such as birth asphyxia, aspiration pneumonia, meconium aspiration syndrome and hypoxicischemic encephalopathy, septicemia. 7.84\% of the studied 102 cases died, who were mainly from the aspiration group.

Conclusion: This study found that meconium-stained babies' prominent clinical features are breathing difficulties, hypoxic-ischemic encephalopathy, features of sepsis, features of pneumonia, and meconium gastritis. Hospitalization was needed in $97.06 \%$ of cases, and $7.8 \%$ of cases died due to associated complications.

Keywords: Meconium-stained amniotic fluid; Meconium aspiration syndrome; Perinatal morbidity; Perinatal mortality

\section{Introduction}

The presence of meconium in amniotic fluid is a potentially serious sign of fetal compromise mortality and morbidities [1,2]. It has been associated with poor perinatal outcomes, including low APGAR scores, increased rate of chorioamnionitis, increased incidence of neonatal intensive care admission, and a high perinatal death rate [3]. Meconium passage is rare before 34 weeks of gestations, and after 37 weeks, its incidence increases steadily with increasing gestational age [5]. Passage of meconium in utero with 
staining of the amniotic fluid occurs $12 \%$ to $16 \%$ of all deliveries [6-8]. The presence of meconium below the vocal cord is known as meconium aspiration. It occurs in $20 \%$ to $30 \%$ of all infants with meconium-stained amniotic fluid [9], with around 12\% mortality [7]. Aspiration can occur in utero with fetal gasping or after birth with the first breaths of life [10].

Meconium aspiration syndrome (MAS) occurs at higher rates in pregnancies beyond 40 weeks, with $34 \%$ of cases born after 40 weeks. In a study in 1996, among 1426 deliveries, 204 deliveries had MSAF, of which thick meconium was present in 141 [13]. From August 1999 to July 2000, in another study, the total number of live births was 3002, and the incidence of meconium-stained amniotic fluid was 8.3\% (249/3002) [15]. MSAF is associated with lots of adverse outcomes of the fetus and has long been considered a bad predictor of fetal outcome. There is no significant data regarding this phenomenon available for our country. So, this cross-sectional observational study evaluates the clinical profiles and outcome of meconium-stained babies.

\section{Method}

This cross-sectional observational study was performed in the Department of Neonatology, Dhaka Medical College Hospital from $1^{\text {st }}$ March 2011 to $31^{\text {st }}$ October 2011. One hundred two neonates with meconium-stained at birth were selected for the study, excluding sick neonates with birth injuries, congenital anomalies, and multiple gestations. Babies' clinical conditions were assessed with APGAR scores at the first and $5^{\text {th }}$ minute, birth weight, gestational age (at birth), signs of perinatal asphyxia, respiratory difficulties, reflex activity, percentage of oxygen saturation, capillary blood glucose (CBG), and requirement of resuscitation after birth. Information about the other related investigations were also recorded. X-ray of the chest was done in suspected cases of meconium aspiration. The outcome of these babies about uneventful recovery, ingestion, cases of aspiration, death cases, and any other complications was recorded. Parents and guardians of the enrolled babies were informed about the study, and written consent was obtained. The Ethical Review Committee of Dhaka Medical College Hospital approved this study. A predefined questionnaire was used to collect data that was then processed and analyzed using the statistical software SPSS (version 24.0). In addition to descriptive statistics, Chi-square and Fisher's Exact tests were performed to find the association between meconium staining and the clinical outcome.

\section{Result}

A total of 102 samples were enrolled for the study. Among them, 99 were admitted to special care baby unit (SCABU) for observation as well as treatment (whenever needed) From the selected sample, 39 (38.2\%) babies had only staining (on the skin, umbilicus, nail), 56 (55\%) babies had staining with ingestion, and 7 (6.8\%) babies had features of aspiration along with staining (Figure 1). Gestational age of majority of the studied patients were between 37 to 42 weeks. The average birth weight was $2.614( \pm 0.355) \mathrm{kg}$. About $56.9 \%$ of cases were male and the rest were female Table 1. Breathing difficulties were present in 24 (61.5\%) cases among 39 cases of only staining, $49(87.5 \%)$ cases among 56 cases of ingestion, and $100 \%$ cases of aspiration. This association between meconium condition and breathing difficulties was statistically significant as the p-value is less than 0.05. Birth asphyxia of babies was not statistically significant. CRT higher than 3 seconds was found in all cases of aspiration. Hypoxic-ischemic encephalopathy were observed significantly for cases of ingestion, while all the cases of aspiration showed poor reflexes. Oxygen saturation was low in all the cases of meconium aspiration. For other cases of staining, poor oxygen saturation was not typical. CBG of babies was not significantly affected by meconium staining. Features of pneumonia was observed in most cases (57.1\%) with ingestion and all the cases of aspiration. This study revealed a significant association between the presence of meconium gastritis and meconium conditions Table 2.

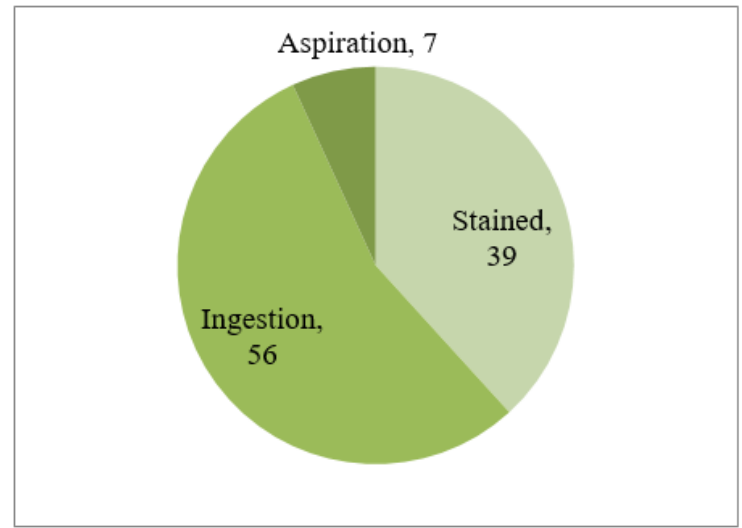

Figure 1: Meconium condition of the studied patients $(n=102)$. 
Table 1: Demographic characteristics of the studied patients $(n=102)$.

\begin{tabular}{|c|c|c|}
\hline \multicolumn{2}{|c|}{ Demographic Characteristics } & Number (\%) \\
\hline \multirow{2}{*}{ Gestational age } & $<37$ weeks & $70(68.6 \%)$ \\
\cline { 2 - 3 } & $37-42$ weeks & $15(14.7 \%)$ \\
\cline { 2 - 3 } & $>42$ weeks & $2.614( \pm 0.355)$ \\
\hline \multirow{2}{*}{ Birth weight $(\mathrm{kg})$} & & $(\mathrm{Mean} \pm \mathrm{SD})$ \\
\hline \multirow{2}{*}{ Gender } & Male & $58(56.9 \%)$ \\
\cline { 2 - 3 } & Female & $44(43.1 \%)$ \\
\hline
\end{tabular}

Table 2: Clinical profile of the studied patients $(n=102)$.

\begin{tabular}{|c|c|c|c|c|c|}
\hline \multirow{2}{*}{\multicolumn{2}{|c|}{$\begin{array}{l}\text { Clinical Features } \\
\text { n (\%) }\end{array}$}} & Only stained $(n=39)$ & Stained with ingestion $(n=56)$ & $\begin{array}{l}\text { Stained with aspiration } \\
\qquad(n=7)\end{array}$ & \multirow[t]{2}{*}{ P-value } \\
\hline & & \multirow{2}{*}{$\begin{array}{c}\text { n (\%) } \\
15(38.5 \%)\end{array}$} & n (\%) & \multirow[b]{2}{*}{$0(0 \%)$} & \\
\hline \multirow{2}{*}{ Breathing Difficulties } & Absent & & $7(12.5 \%)$ & & \multirow{2}{*}{$0.004^{*}$} \\
\hline & Present & $24(61.5 \%)$ & $49(87.5 \%)$ & $7(100 \%)$ & \\
\hline \multirow{2}{*}{ Birth Asphyxia } & Absent & $12(30.8 \%)$ & $19(33.9 \%)$ & $1(14.3 \%)$ & \multirow{2}{*}{0.57} \\
\hline & Present & $27(69.2 \%)$ & $37(66.1 \%)$ & $6(85.7 \%)$ & \\
\hline \multirow{2}{*}{$\begin{array}{l}\text { CRT (Capillary Refill } \\
\text { Time) }\end{array}$} & $<3 \mathrm{sec}$ & $36(92.3 \%)$ & $51(91.1 \%)$ & $0(0 \%)$ & \multirow{2}{*}{$<0.001^{*}$} \\
\hline & $\geq 3 \mathrm{Sec}$ & $3(7.7 \%)$ & $5(8.9 \%)$ & $7(100 \%)$ & \\
\hline \multirow{3}{*}{ Reflex Activities } & Weak & $3(7.7 \%)$ & $22(39.3 \%)$ & $7(100 \%)$ & \multirow{3}{*}{$<0.001^{*}$} \\
\hline & Moderate & $15(38.5 \%)$ & $28(50 \%)$ & $0(0 \%)$ & \\
\hline & Good & $21(53.8 \%)$ & $6(10.7 \%)$ & $0(0 \%)$ & \\
\hline \multirow{3}{*}{$\mathrm{PaO}_{2}$} & $<60 \%$ & $3(7.7 \%)$ & $5(8.9 \%)$ & $7(100 \%)$ & \multirow{3}{*}{$<0.001^{*}$} \\
\hline & $60 \%-80 \%$ & $0(0 \%)$ & $30(53.6 \%)$ & $0(0 \%)$ & \\
\hline & $80 \%-95 \%$ & $36(92.3 \%)$ & $21(37.5 \%)$ & $0(0 \%)$ & \\
\hline \multirow{2}{*}{ CBG } & $<2.6 \mathrm{mmol} / \mathrm{L}$ & $3(7.7 \%)$ & $4(7.1 \%)$ & $2(28.6 \%)$ & \multirow{2}{*}{0.161} \\
\hline & $2.6-7.8 \mathrm{mmol} / \mathrm{L}$ & $36(92.3 \%)$ & $52(92.9 \%)$ & $5(71.4 \%)$ & \\
\hline \multirow{2}{*}{$\begin{array}{l}\text { Features of Pneu- } \\
\text { monia }\end{array}$} & Present & $3(7.7 \%)$ & $32(57.1 \%)$ & $7(100 \%)$ & \multirow{2}{*}{$<0.001^{*}$} \\
\hline & Absent & $36(92.3 \%)$ & $24(42.9 \%)$ & $0(0 \%)$ & \\
\hline \multirow{2}{*}{ Meconium Gastritis } & Present & $0(0 \%)$ & $18(32.1 \%)$ & $3(42.9 \%)$ & \multirow{2}{*}{$<0.001^{*}$} \\
\hline & Absent & $39(100 \%)$ & $38(67.9 \%)$ & $4(57.1 \%)$ & \\
\hline
\end{tabular}

*Statistically significant

Table 3: Outcome of the studied patients $(n=102)$.

\begin{tabular}{|c|c|c|c|}
\hline Meconium Condition & Survived & Died & P-value \\
\hline Stained $(\mathrm{n}=39)$ & $39(100 \%)$ & $0(0 \%)$ & \\
\hline Ingestion $(\mathrm{n}=56)$ & $51(91.1 \%)$ & $5(8.9 \%)$ & $<0.001^{*}$ \\
\hline Aspiration $(\mathrm{n}=7)$ & $4(57.2 \%)$ & $3(42.8 \%)$ & \\
\hline
\end{tabular}

*Statistically significant

Among the 102 study cases, 8 (7.84\%) cases died, and 94 $(92.16 \%)$ cases survived. $42.8 \%$ cases of aspiration and $8.9 \%$ cases of ingestion died. Hospitalization was required for most of the cases of meconium staining. Among the 102 study samples, 97.06\% of cases were hospitalized. All the cases of ingestion and aspiration were hospitalized for a period of $72-96$ hours on an average.

\section{Discussion}

The present study findings were discussed and compared with previously published relevant studies regarding the presence of meconium, clinical profiles, and outcome of stained babies. In this current study, it was observed that other demographic characteristics like gender and birth weight of the babies did not significantly affect meconium staining.

In a recent study, Shukla and Swapna found $58.2 \%$ of cases developed respiratory distress [11]. However, another study by Divia showed that respiratory distress was present in about $8.4 \%$ of cases [12]. The current study also finds that a very high percentage $(78.4 \%)$ of cases developed respiratory distress. MAS is a well- 
known complication of MSAF with incidence varies from 1-6.8\% in babies born with MSAF [4]; in our study, it was found in $6.9 \%$ of total cases.

Birth asphyxia was frequently observed in meconium-stained babies. In this study, $68.2 \%$ of cases had birth asphyxia, though this association between birth asphyxia and meconium condition was not statistically significant. Gupta et al. [13] found that birth asphyxia was significantly high in meconium-stained amniotic fluid, whereas Khatun et al. [16] found only $12.9 \%$ cases in their study. Stained with ingestion and aspiration cases also showed very poor neurological reflexes (hypoxic-ischemic encephalopathy). This study finds $31.4 \%$ of cases of hypoxic-ischemic encephalopathy, but Shukla and Swapna [11] only found $2.8 \%$ of such cases. A study with a larger study size from multiple centers might explain this anomaly. Features of shock (CRT $>3$ seconds) was observed in all aspirations cases. Oxygen saturation was low $\left(\mathrm{PaO}_{2}<60 \%\right)$ in all 7 cases of aspiration. For other cases of only staining, poor oxygen saturation was not typical. Features of pneumonia was present in $57.1 \%$ of cases of ingestion and among all the cases of aspiration.

According to Bhatia et al. [15], mortality ranges from $6 \%$ to $40 \%$ for meconium-stained babies. Gupta et al. [13] found $4.9 \%$ mortality in the meconium-stained amniotic fluid group compared to $2.8 \%$ mortality in control. The current study result was also consistent with the abovementioned studies having a mortality rate of $7.84 \%$. Cases that died were mainly from ingestion and aspiration groups.

Hospitalization was required for most of the cases of meconiumstained babies. Among the 102 study samples, 97.06\% of cases were hospitalized for observation and necessary resuscitation, and $2.04 \%$ did not require any resuscitation. Cases that did not require hospitalization were from the category of only staining with meconium. In our study, most of the hospitalized babies were discharged within 72 to 96 hours of life without developing any complications. Shukla and Swapna also observed similarly for their hospitalized cases [11].

\section{Conclusion}

This study found that meconium-stained babies' prominent clinical features are breathing difficulties, hypoxic-ischemic encephalopathy, features of sepsis, features of pneumonia, and meconium gastritis. MAS was found in $6.9 \%$ of the cases. Hospitalization was needed in $97.06 \%$ of cases, and $7.8 \%$ of cases died due to associated complications.

\section{Acknowledgement}

We want to thank all the faculties, fellowship students, residents, and staff of the Department of Neonatology, Dhaka Medical College
Hospital and the Department of Pediatric Gastroenterology, Hepatology \& Nutrition, Dhaka Shishu (Children) Hospital, for their technical and administrative assistance. We also want to thank all the parents of our patients who were very cooperative throughout the study period.

\section{Conflict of Interest}

We, the authors declare that we have no conflicting interests.

\section{References}

1. Berkus MD, Langer O, Samuelloff A, Zenakis EM, Field NT, et al. (1994) Meconium stained amniotic fluid: Increased risk for adverse neonatal outcome. Obstet Gynecol 84: 115-120.

2. Nathan L, Lenevo KJ, Camody TJ, Kelly MA, Sherman ML (1994) Meconium: a 1990s perspective on an obstetric hazard. Obstet Gynecol 83: 329-332.

3. Ahanya SN, Lakshmanan J, Morgan BL, Ross MG (2005) Meconium passage in utero: mechanisms, consequences, and management. Obstet Gynecol Surv 60: 45-56.

4. Wiswell TE (2001) Handling the meconium stained infant. Semin Neonatol 6(3): 225-231.

5. Wiswell TE, Henley MA (1992) Intratracheal suctioning, systemic infection and the meconium aspiration syndrome. Pediatrics 89: 203206.

6. Cleary GM, Wiswell TE (1998) Meconium-stained amniotic fluid and the meconium aspiration syndrome - An update. Pediatr Clin North Am 45: 511-529.

7. Maymon E, Chaim W, Furman B, Ghezzi F, ShohamVardi I, et al. (1998) Meconium stained amniotic fluid in very low risk pregnancies at term gestation. Eur J Obstet Gynecol Reprod Biol 80: 169-173.

8. Wiswell TE, Bent RC (1993) Meconium staining and the meconium aspiration syndrome. Unresolved issues. Pediatr Clin North Am 40: 955981.

9. Kligner MC, Kruse J (1999) Meconium aspiration syndrome: Pathophysiology and prevention. J Am Board Fam Pract 12: 450-466.

10. Romero R, Hanaoka S, Mazor M, Athanassiadis AP, Callahan R, et al. (1991) Meconium-stained amniotic fluid: a risk factor for microbial invasion of the amniotic cavity. Am J of Obstet Gynecol 164(3): 859-862.

11. Shukla OS, Swapna ST (2019) Study of risk factors, clinical profile, and outcome in meconium-stained deliveries. Indian J Child Health 6(5): 213-216.

12. Divia A (2018) Study on Risk Factors and Perinatal Outcome in Meconium Stained Liquor, Dissertation pp. 64-70.

13. Gupta V, Bhatia BD, Mishra OP (1996) Meconium stained amniotic fluid: antenatal, intrapartum and neonatal attributes. Indian Pediatrics 33(4): 293-297

14. Patil KP, Swamy MK, Samatha K (2006) A one year cross sectional study of management practices of meconium stained amniotic fluid and perinatal outcome. Obstet Gynecol India 56: 128-130.

15. Bhatia BD, Gupta V, Dey PK (1996) Meconium aspiration syndrome: current concepts. Indian J Matern Child Health 7(1): 1-7.

16. Khatun M (2005) Meconium Staining liquor and its correlative with fetal outcome within seven days of birth in Dhaka Medical College. Dissertation. Bangladesh College of Physicians and Surgeons pp. 39-43. 